\title{
12th INTERNATIONAL WORKSHOP ON MULTIPLE PREGNANCY
}

\author{
From curiosity to epidemic
}

\section{ASSISI, ITALY, JUNE 24-27, 1999}

\author{
Honorary Presidents
}

Louis and Donald Keith (Chicago, USA)

\author{
Presidents
}

Gian Carlo Di Renzo (Perugia, Italy)

Isaac Blickstein (Rehovat, Israel)

Scientific Secretariat

Centre of Perinatal Medicine

Dept. of Obstetrics and Gynecology

University of Perugia

P.O.Box 1433, 06122 Perugia-Italy

Tel. ++39-075-5720 563/5720 574

Fax ++39-075-5729 271

Email: direnzo@unipg.it 